Fukushima J. Med. Sci.,

Vol. 63, No. 1, 2017

[Review]

\title{
Early diagnosis of chronic pancreatitis : understanding the factors associated with the development of chronic pancreatitis
}

\author{
Akane Yamabe, Atsushi Irisawa, Goro Shibukawa, Ai Sato, Mariko Fujisawa, \\ Noriyuki Arakawa, Yoshitsugu Yoshida, Yoko Abe, Ryo Igarashi, \\ Takumi Maki and Shogo Yamamoto
}

Department of Gastroenterology, Aizu Medical Center, Fukushima Medical University

(Received November 1, 2016, accepted March 14, 2017)

\begin{abstract}
The prognosis of advanced chronic pancreatitis $(\mathrm{CP})$ is poor with the mortality rate approximately two-fold higher than the general population according to a survey of the prognosis of CP. From this standpoint, the concept of early CP was propagated in Japan in 2009 to encourage the medical treatment for the earlier stages of CP. That is, picking up the patients suspicious for early $\mathrm{CP}$ and then providing medical treatment for them are very important not only for patients, but also for health care economics. In this review, we described some potential factors associated with the development of CP (alcohol, smoking, past history of acute pancreatitis, aging, gallstone, and gender) that are extremely important to discover patients with early-stage $\mathrm{CP}$.
\end{abstract}

Key words : chronic pancreatitis, endoscopic ultrasound, risk factor

\section{Introduction}

Understanding of the pathophysiology and therapy of chronic pancreatitis (CP) has innovatively advanced since Thomas Cawley first reported $\mathrm{CP}$ in $1,788^{1)}$. However, the prognosis of $\mathrm{CP}$ is poor with the mortality rate approximately two-fold higher than the general population according to a survey of the prognosis of CP. A worldwide epidemiological survey in 1,993 showed that the incidence rate of pancreatic cancer is as high as 26 -fold of the age/ sex/country-standardized predicted incidence ${ }^{2)}$. Therefore, cancer develops relatively frequently in $\mathrm{CP}$ but its diagnosis becomes difficult in advanced $\mathrm{CP}$ due to increased fibrosis and pancreatic calculi3). Although it has been understood that early diagnosis and proper treatment of $\mathrm{CP}$ are extremely important, diagnosis has been difficult because the clinical features of early $\mathrm{CP}$ are unclear ; diagnostic imaging techniques capable of easily detecting minor pancreatic parenchyma/duct abnormalities have not been established. Even in the current clinical settings, patients having abdominal symptoms or exhibiting abnormal functional testing results are frequently found to have advanced CP. However, the advance in endoscopic ultrasonography (EUS) in recent years has allowed less invasive examinations while precisely capturing slight changes in the so-called undetectable organ, casting light on the early stages of $\mathrm{CP}^{4-8}$. Against such backdrop, the concept of early-stage CP was propagated in Japan in 2009 to encourage the medical treatment for the earlier stages of $\mathrm{CP}^{9)}$ (Table 1, Fig. 1). In order to understand whether the disease that meets the criteria for early-stage $\mathrm{CP}$ actually progresses to advanced $\mathrm{CP}$, prospective studies are needed. However, at present, picking up the patients suspicious for early $\mathrm{CP}$ and providing medical treatment for them are very important not only for patients, but also for health care economics. Here, we review potential factors associated with the development of $\mathrm{CP}$ that are extremely important to discover patients with earlystage $\mathrm{CP}$.

Corresponding author : Atsushi Irisawa, MD, PhD E-mail : irisawa@fmu.ac.jp

https://www.jstage.jst.go.jp/browse/fms http://www.fmu.ac.jp/home/lib/F-igaku/ 
Table 1. Clinical diagnostic criteria for early chronic pancreatitis : More than two clinical signs + Imaging findings ${ }^{9)}$
Clinical signs
1) Repeated upper abdominal pain
2) Abnormal pancreatic enzyme levels in the serum or urine
3) Abnormal pancreatic exocrine function
4) Continuous heavy drinking of alcohol equivalent to or more than $80 \mathrm{~g}$ /day of pure ethanol

Imaging findings (Either $a$ or $b$ )

a. More than two among the seven features including any of (1)-(4)

(1) Lobularity with honeycombing

(2) Lobularity without honeycombing

(3) Hyperechoic foci without shadowing

(4) Stranding

(5) Cysts

(6) Dilated side branches

(7) Hyperechoic main pancreatic duct (MPD) margin

b. Irregular dilatation of more than 3 duct branches on ERP
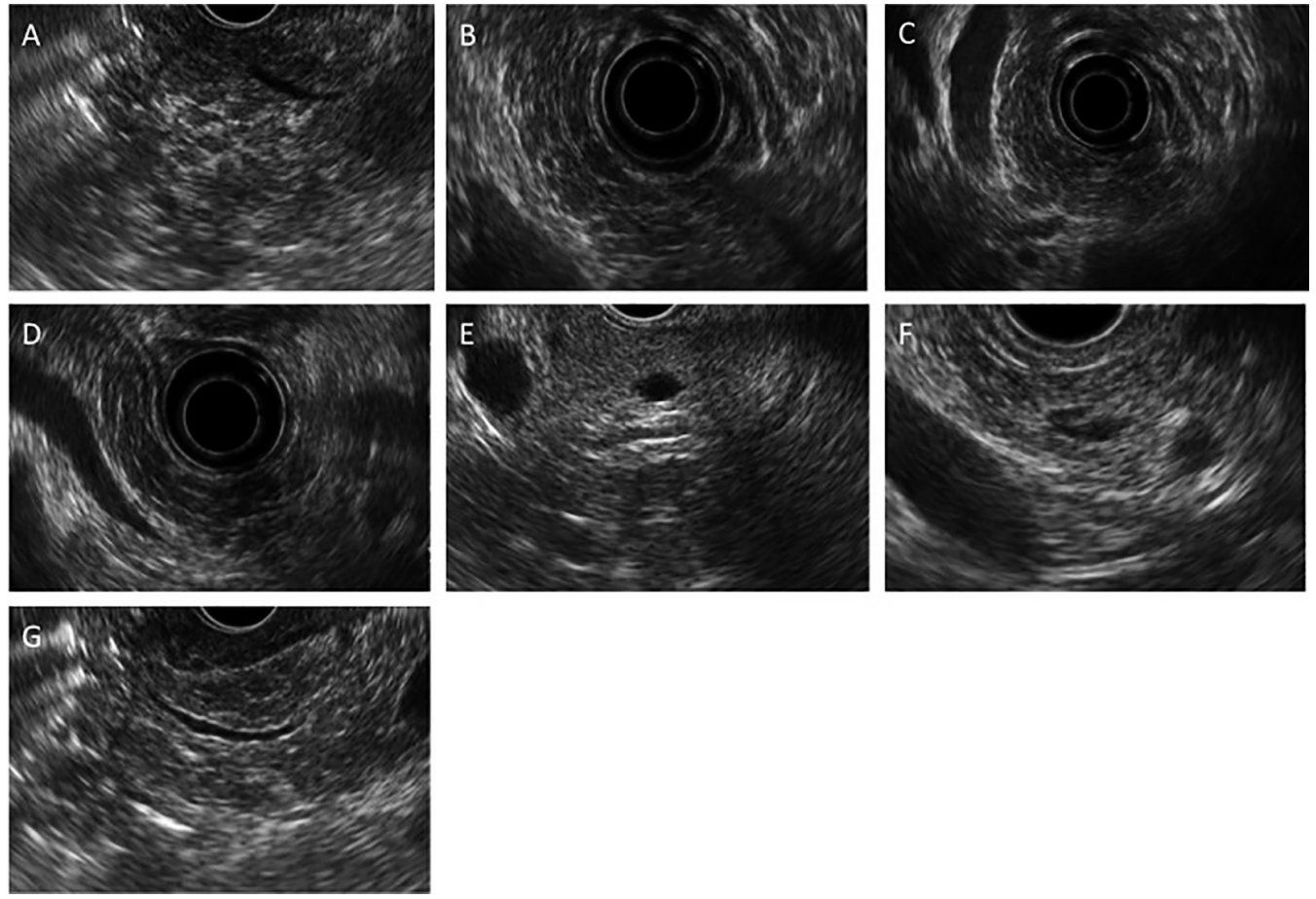

Fig. 1. EUS findings of early chronic pancreatitis

A : Lobularity with honeycombing

B : Lobularity without honeycombing

C : Hyperechoic foci without shadowing

D : Stranding

E : Cyst

F : Dilated side branches

G : Hyperechoic MPD margin

Factors associated with the development of CP

\section{Drinking (Table 2, 3)}

Alcohol has been commonly reported as a risk factor for CP. Alcohol consumption (80-150 g/day) is related to $60-80 \%$ of cases and patients usually have a long history of alcohol abuse (6-12 years $)^{10-13)}$. Yadav et $a l .{ }^{14)}$ reported that compared with abstaining or light drinking, very heavy drinking was signifi- 
Table 2. Main factors associated with the development of CP

\begin{tabular}{|c|c|c|c|}
\hline Authors & Year & & Odds ratio \\
\hline \multicolumn{4}{|l|}{ Drinking } \\
\hline Corrao et $a l .{ }^{15)}$ & 2004 & Drinkers of $25 \mathrm{~g} /$ day of alcohol vs. non-drinkers & 1.34 \\
\hline Corrao et al. ${ }^{15)}$ & 2004 & Drinkers of $50 \mathrm{~g} /$ day of alcohol vs. non-drinkers & 1.78 \\
\hline Lin Y et al. ${ }^{13)}$ & 2001 & Drinkers of 50-99 g/day of alcohol vs. non-drinkers & 5.7 \\
\hline Corrao et $a l .{ }^{15)}$ & 2004 & Drinkers of $100 \mathrm{~g} /$ day of alcohol vs. non-drinkers & 3.19 \\
\hline Lin Y et al..$^{13)}$ & 2001 & Drinkers of $\geq 100 \mathrm{~g} /$ day of alcohol vs. non-drinkers & 11.2 \\
\hline \multicolumn{4}{|l|}{ Smoking } \\
\hline Nakamura T et al. ${ }^{22)}$ & 2012 & Smokers vs. non-smokers & 7.8 \\
\hline
\end{tabular}

Table 3. Main factors associated with the risks for EUS pancreatic abnormalities

\begin{tabular}{cccc}
\hline Authors & Year & Odds ratio \\
\hline Drinking & & & \\
Yusoff et $a l .{ }^{19)}$ & 2004 & Heavy alcohol ingestion vs. non-drinkers & 5.1 \\
\hline Smoking & & & \\
Yusoff et al. ${ }^{19)}$ & 2004 & Heavy smoking vs. non-smokers & 1.7 \\
\hline
\end{tabular}

cantly associated with $\mathrm{CP}$ (odds ratio [OR], $3.10 ; 95 \%$ confidence interval [CI], 1.8-5.1). In addition, an epidemiological survey in Japan showed a significant dose-response relationship, where the higher the cumulative alcohol consumption (alcohol consumption per day $\times$ years of drinking) is, the higher is the risk for $\mathrm{CP}$; this indicates that high long-term alcohol consumption increases the risk for CP. In fact, a case-control study conducted in Japan $^{13)}$ demonstrated that the OR of drinkers who had 50-99 $\mathrm{g} /$ day of alcohol and those who had $\geq 100$ $\mathrm{g} /$ day compared to non-drinkers were 5.7 and 11.2, respectively ; this shows that the risk elevates in a dose-dependent manner. Corrao et al. ${ }^{15)}$, in a metaanalysis of drinking and 15 diseases including $\mathrm{CP}$, stated that the relative risks for $\mathrm{CP}$ in drinkers of 25 , 50 , and $100 \mathrm{~g} /$ day compared to non-drinkers were $1.34,1.78$, and 3.19 , respectively demonstrating a dose-dependent relationship : the risk for $\mathrm{CP}$ elevates as the alcohol assumption increases. On the other hand, there is a study reporting that less than $10 \%$ of heavy drinkers develop $\mathrm{CP}^{16)}$. Thus, it is also possible to interpret alcohol as only one of the factors for developing CP albeit a very important factor for finding $\mathrm{CP}$ in the early stages.

The relationship between drinking and EUS CP findings has also been reported. Thuler $e t a l{ }^{17)}$ compared alcoholic and non-alcoholic groups and demonstrated that alcoholic patients had significantly $(P<0.001)$ more EUS abnormalities compared to non-alcoholic patients. Moreover, the two most common features shared by alcoholic and non-alcoholic patients, according to the Catalano et al. ${ }^{18)}$, were heterogeneous echo-pattern and echogenic duct wall. Considering the Sahai $e t a l{ }^{6}{ }^{6}$, the most common features for the alcoholic group were hyperechoic foci and hyperechoic duct while the nonalcoholic group showed more hyperechoic foci and hyperechoic strands. Yusoff et al. ${ }^{19)}$ also demonstrated that heavy alcohol ingestion was associated with more EUS features of CP (OR 5.1 ; 95\% CI, 3.1-8.5). Moreover, Sahai et al. ${ }^{20)}$ reported that, in the analysis of alcohol consumption and EUS findings in 1,157 individuals, there were more EUS findings in $\mathrm{CP}$ as the alcohol consumption increased. Petrone $e t a l .^{21)}$ demonstrated that even at a low dose, alcohol consumption significantly increased the risk of hyperechoic parenchymal foci, main pancreatic duct (MPD) dilatation, and wall hyperechogenicity.

From these reports, asymptomatic, alcoholic patients might have pancreatic abnormalities that may be missed by other procedures, and EUS might be useful in screening patients for suspected early stage CP. We can also argue, based on these reports, that EUS is able to show early structural damage to the pancreas.

\section{Smoking (Table 2, 3)}

According to a case-control study in Japan, the risk for $\mathrm{CP}$ in smokers was higher (OR : 7.8) compared to non-smokers and smoking is shown to be 
an independent factor from drinking ${ }^{22)}$. Sankaran $e t$ $a l{ }^{23)}$ analyzed 14 studies, which included a total of 8,492 patients, and reported that alcohol use and smoking to be the largest risk factors for the development of $\mathrm{CP}$ with pooled prevalence values of $65 \%$ (95\% CI, 48\%-56\%) and 61\% (95\% CI, 47\%-73\%), respectively. Yadav et al. ${ }^{14)}$ reported results from a multicenter study, and concluded that smoking was an important factor causing an increase incidence of CP. In that study, prior and current smoking were reported by $71.4 \%$ and $47.3 \%$ of $\mathrm{CP}$ patients, respectively. There are studies reporting that in patients who developed idiopathic $\mathrm{CP}$ at 35 years of age or older, calcification of pancreatic calculi occurred earlier and more frequently, accelerating the progression of $\mathrm{CP}$ in smokers compared to nonsmokers $^{24,25)}$. Law et al. ${ }^{26)}$ also analyzed the relationship between $\mathrm{CP}$ and smoking and demonstrated a significant positive correlation between higher total smoking amounts and higher rates of being diagnosed with CP. They concluded that smoking is a distinct independent risk factor from drinking. Andriulli et $a{ }^{27}{ }^{27}$ reported that since the relative risk for $\mathrm{CP}$ in smokers to non-smokers was 2.8 , whereas that in former smokers was reduced to 1.4 ; smoking cessation significantly decreases the relative risk for CP. Yusoff et al. ${ }^{19)}$ also mentioned that one of the strongest independent predictors of severe EUS pancreatic abnormalities was heavy smoking (OR 1.7 ; 95\% CI, 1.2-2.4). Petrone et al..$^{21)}$ examined the relation of smoking and EUS findings and demonstrated that smoking was associated with an increased risk of hyperechoic parenchymal foci. Although smoking is frequently less recognized as a cause of CP compared to alcohol, it is an important risk factor.

\section{Past history of acute pancreatitis}

Various theories about the transition to $\mathrm{CP}$ after acute pancreatitis are proposed in the treatment guidelines for acute pancreatitis. However, at present, the necrosis-fibrosis theor ${ }^{28)}$, that fibrosis after necrosis causes changes in the pancreatic duct which results in the progression to $\mathrm{CP}$ by causing the efflux disorder of pancreatic juice, is supported. In an analysis of the long-term outcomes in patients with acute pancreatitis in Japan ${ }^{29)}$, the recurrence rate of all pancreatitis was $20.3 \%$ and the transition to $\mathrm{CP}$ was observed in $14.8 \%$ of patients. "Alcoholic" was the highest cause of the recurrence rate of pancreatitis $(32.4 \%)$ as well as the transition rate to CP (26.0\%). The transition rate to CP was $45 \%$ in patients who had recurrence twice, while it was
$61.4 \%$ in those who had recurrence three times. Thus, the transition rate was high in patients who had multiple recurrences. Yasuda et al. ${ }^{30)}$ evaluated the outcome of severe acute pancreatitis and reported that transition to $\mathrm{CP}$ was noted in $22 \%$ of patients. In that study, the transition rate was higher in those with severe acute alcoholic pancreatitis than in those with severe acute biliary pancreatitis. In the report by Ammann et al. ${ }^{31}$, among 140 cases of alcoholic recurrent acute pancreatitis, $78 \%$ progressed to CP. Lankisch et al. ${ }^{32)}$ observed that $95 \%$ of the cases of $\mathrm{CP}$ had progressed from acute alcoholic pancreatitis. They also reported that the cumulative risk for the development of $\mathrm{CP}$ was $13 \%$ within 10 years and $16 \%$ within 20 years; the risk of $\mathrm{CP}$ in those who survived a second episode of acute pancreatitis was $38 \%$ within 2 years. Therefore, it is clear that the recurrent acute alcoholic pancreatitis progresses to $\mathrm{CP}$. The understanding of this process is extremely important in the diagnosis and treatment of early CP. On the other hand, the investigations from the USA ${ }^{33}$ showed a transition from acute to $\mathrm{CP}$ in $24.1 \%$ of patients after $3-5$ years and $32.3 \%$ after $3-4$ years, respectively. In this study, transition also occurred occasionally in patients with non-alcohol-induced pancreatitis. Nøjgaard $e t ~ a l .{ }^{34)}$ reported that nicotine misuse increased the risk of progression from acute to $\mathrm{CP}$ substantially. Alcohol remains the most important factor for the transition from acute pancreatitis to $\mathrm{CP}$, but cessation of smoking as well as drinking are needed to aid in preventing $\mathrm{CP}$. On the other hand, Kumar $e t ~ a l .{ }^{35)}$ examined the risk factors associated with pediatric $\mathrm{CP}$. They clarified that the majority of children with CP (123 of 146 [84\%]) reported prior recurrent episodes of acute pancreatitis. Based on the analysis in children, the transition from acute pancreatitis to $\mathrm{CP}$ may occur spontaneously or may be affected by factors other than drinking and smoking.

\section{Aging}

Ikeda et al ${ }^{36)}$ analyzed the incidence of subclinical morphologic changes in the pancreas detected by screening ultrasonography in relation to the background factors of 130,951 subjects. In that study, an age-dependent increase in the incidence of MPD dilatation and cystic lesions was observed in both sexes whereas that of calcification was observed only in men. Petrone et $a{ }^{21)}$ demonstrated that advanced age was significantly associated with an increased risk of MPD dilatation. In addition, Rajan et $a l .{ }^{37)}$ analyzed the relationship between age and 
the number of EUS findings in $\mathrm{CP}$ and observed that the number of EUS findings tended to increase with advancing age particularly in patients age 60 years and older.

Thus, it appears undeniable that aging is associated with the development of $\mathrm{CP}$. However, changes in the pancreatic parenchyma and duct specifically due to aging should be taken into account as a factor in progression to $\mathrm{CP}$. In fact, changes in the pancreas due to aging have been pathologically demonstrated. Detlefsen et $a l .{ }^{38)}$ screened pancreas specimens for the presence and pattern of fibrosis to determine the relationship between fibrosis, age, and duct lesions. In 89 postmortem specimens from individuals without any known pancreatic disease (age range 20-86 years), they found that fibrotic changes were significantly more common in individuals older than 60 years and the "normal" pancreas develops a specific type of focally accentuated fibrosis that is highly age related. In addition, Chantarojanasiri et al..$^{39)}$ examined the relation of aging and pancreatic changes in autopsy and imaging studies. They reported that the pancreatic volume was found to decrease with advancing age, and the pancreatic ductal structure was described as having a wide range of normal variations, although many other studies have shown a tendency toward enlargement with advancing age.

On EUS, the aging pancreas may exhibit abnormal findings similar to CP. Janssen et al..$^{40)}$ examined the effect of aging on pancreas elasticity by using semiquantitative EUS elastography; they reported that, on elastography, the pancreas become significantly harder during aging, but remain softer compared to that observed in CP. However, at present, it is difficult to definitively distinguish whether EUS findings in CP, considered to represent histological fibrosis, are age related. Thus, one should carefully diagnose $\mathrm{CP}$ in the elderly to avoid overdiagnosis.

\section{Gallstone}

Some reports showed an association between gallstones and CP. In a Chinese study, Wang et al. ${ }^{41)}$ reported that the main etiologies of $\mathrm{CP}$ were alcohol $(35.11 \%)$, biliary stones $(34.36 \%)$, hereditary (7.22\%), and idiopathic (12.90\%); alcohol and biliary stones account for $70 \%$ of the these causes. Another Chinese clinical study ${ }^{42}$ has also shown that the main cause of $\mathrm{CP}$ in China seems to be cholelithiasis, cholecystitis, or diseases of the choledochus. Hardt et $a l .{ }^{43)}$, in an endoscopic retrograde cholangiopancreatography (ERCP) study, reported that $77 \%$ of gallstone patients and only $47 \%$ of non-gallstone patients were found to have $\mathrm{CP}$ according to the Cambridge classification. According to the findings of Misra et $a .^{44}{ }^{44}$, it seems that patients with gall stones tend to develop CP. In addition, Okazaki et al. ${ }^{45)}$ performed a clinical study, in which they endoscopically measured pressures of the pancreatic duct and the sphincter of Oddi in patients with alcoholic pancreatitis, gallstone pancreatitis, and idiopathic $\mathrm{CP}$, and controls. In that study, patients with alcoholic, gallstone-associated, and idiopathic $\mathrm{CP}$ had significantly higher pressures of the pancreatic duct and frequencies of the papillary sphincter waves compared to controls. Joergensen et al. ${ }^{46)}$ reported a girl with gall stones associated with $\mathrm{CP}$ and an impacted gall stone in the ampulla of Vater. The passage of gallstones into the common bile duct may be involved in the etiology of gallstones pancreatitis. On the other hand, Yadav et $a l .{ }^{47)}$ reported that gallstones do not cause CP. Gallstones are the most common cause of acute pancreatitis. Amrnann ${ }^{48)}$ classified recurrent acute pancreatitis based on the clinical causes and reported that acute gallstone pancreatitis can become recurrent pancreatitis but it never progresses to $C P$. In a Japanese study ${ }^{29)}$, the transition from acute pancreatitis to $\mathrm{CP}$ was noted in $14.8 \%$; it was high (26.0\%) in alcoholic pancreatitis and low (1.7\%) in gallstone pancreatitis. According to these past reports, the association of gallstones with $\mathrm{CP}$ remains controversial.

\section{Gender}

Durbecet et al ${ }^{49)}$ reported that before symptoms related to $\mathrm{CP}$ emerged, men consumed $1,161 \mathrm{~L}$ of alcohol over 18 years on average, while women only consumed $695 \mathrm{~L}$ over 11 years on average; this suggests that women are more susceptible to develop alcoholic pancreatitis. Possible factors causing such gender differences include the different drinking styles, genetics, and smaller liver and muscles in women facilitating an increase in blood alcohol levels. The gender differences may need to be taken into account when setting the amount of alcohol consumption at which drinking becomes a risk. Sankaran $e t ~ a l{ }^{23)}$ reported that men were more likely compared to women to transition from acute pancreatitis to CP. There were some reports regarding the relations of gender and ultrasonographic findings. Ikeda et $a l .{ }^{36)}$ analyzed the subclinical morphologic changes in the pancreas on screening ultrasonography of 130,951 subjects in relation to their incidence and background factors. In that study, the incidence of MPD dilatation and calcification was 
significantly higher in men $(p<0.0001)$, whereas cystic lesions were significantly more frequent in women $(\phi<0.01)$. Petrone $e t a l^{21)}$ also demonstrated that male gender was significantly associated with an increased risk of MPD dilatation.

\section{Conclusion}

Although a method that definitively diagnoses early-stage $\mathrm{CP}$ has not been established, such a clinical stage is surely present during the progression of CP. Findings provided by the current literature review will add a considerable contribution to the understanding and diagnosing early stage $\mathrm{CP}$.

\section{References}

1. Cawley T. A singular case of diabetes, consisting entirely in the quality of the urine ; with an inquiry into the different theories of that disease. London Medical J, 9 : 286-308, 1788.

2. Lowenfels AB, Maisonneuve P, Cavallini G, et al. Pancreatitis and the risk of pancreatic cancer. International Pancreatitis Study Group. N Engl J Med, 328 : 1433-1437, 1993.

3. Raimondi S, Lowenfels AB, Morselli-Labate AM, et al. Pancreatic cancer in chronic pancreatitis; aetiology, incidence, and early detection. Best Pract Res Clin Gastroenterol, 24 : 349-358, 2010.

4. Wiersema MJ, Hawes RH, Lehman GA, et al. Prospective evaluation of endoscopic ultrasonography and endoscopic retrograde cholangiopancreatography in patients with chronic abdominal pain of suspected pancreatic origin. Endoscopy, 25 : 555-654, 1993.

5. Catalano MF, Geenen JE. Diagnosis of chronic pancreatitis by endoscopic ultrasonography. Endoscopy, 30 : A111-115, 1998.

6. Sahai AV, Zimmerman M, Aabakken L, et al. Prospective assessment of the ability of endoscopic ultrasound to diagnose, exclude, or establish the severity of chronic pancreatitis found by endoscopic retrograde cholangiopancreatography. Gastrointest Endosc, 48 : 18-25, 1998.

7. Irisawa A, Katakura K, Ohira $\mathrm{H}$, et al. Usefulness of endoscopic ultrasound to diagnose the severity of chronic pancreatitis. J Gastroenterol, 42: 9094, 2007.

8. Catalano MF, Sahai A, Levy M, et al. EUS-based criteria for the diagnosis of chronic pancreatitis : the Rosemont classification. Gastrointest Endosc, 69 : 1251-1261, 2009.

9. Shimosegawa T, Kataoka K, Kamisawa T, et al. The revised Japanese clinical diagnostic criteria for chronic pancreatitis. J Gastroenterol, 45 : 584-
591, 2010.

10. Steer ML, Waxman I, Freedman S. Chronic pancreatitis. N Engl J Med, 332 : 1482-1490, 1995.

11. Etemad B, Whitcomb DC. Chronic pancreatitis : diagnosis, classification, and new genetic developments. Gastroenterology, 120 : 682-707, 2001.

12. Talamini G, Bassi C, Falconi M, et al. Alcohol and smoking as risk factors in chronic pancreatitis and pancreatic cancer. Dig Dis Sci, 44 : 1303-1311, 1999.

13. Lin Y, Tamakoshi A, Hayakawa T, et al. Associations of alcohol drinking and nutrient intake with chronic pancreatitis : findings from a case-control study in Japan. Am J Gastroenterol, 96 : 26222627, 2001.

14. Yadav D, Hawes RH, Brand RE, et al. Alcohol consumption, cigarette smoking, and the risk of recurrent acute and chronic pancreatitis. Arch Intern Med, 169 : 1035-1045, 2009.

15. Corrao G, Bagnardi V, Zambon A, et al. A metaanalysis of alcohol consumption and the risk of 15 diseases. Prev Med, 38 : 613-619, 2004.

16. Lankisch PG, Lowenfels AB, Maisonneuve P. What is the risk of alcoholic pancreatitis in heavy drinkers? Pancreas, 25 : 411-412, 2001.

17. Thuler FP, Costa PP, Paulo GA, et al. Endoscopic Ultrasonography and Alcoholic Patients : Can One Predict Early Pancreatic Tissue Abnormalities? JOP, 6 : 568-574, 2005.

18. Catalano MF, Lahoti S, Geenen JE, et al. Prospective evaluation of endoscopic ultrasonography, endoscopic retrograde pancreatography, and secretin test in the diagnosis of chronic pancreatitis. Gastrointest Endosc, 48 : 11-17, 1998.

19. Yusoff IF, Sahai AV. A prospective, quantitative assessment of the effect of ethanol and other variables on the endosonographic appearance of the pancreas. Clin Gastroenterol Hepatol, 2 : 405409, 2004.

20. Sahai A. How much alcohol is required to produce EUS chronic pancreatitis? A prospective, blinded, quantitative assessment of the effect of alcohol intake in 1,157 patients. Gastrointest Endosc, 55 : AB241, 2002.

21. Petrone MC, Arcidiacono PG, Perri F, et al. Chronic pancreatitis-like changes detected by endoscopic ultrasound in subjects without signs of pancreatic disease : do these indicate age-related changes, effects of xenobiotics, or early chronic pancreatitis? Pancreatology, 10 : 597-602, 2010.

22. Nakamura T, Ito T, Maruyama K, et al. Japanese guideline for abstinence and lifestyle in patients with chronic pancreatitis : problems and landscape. The Journal of Japan Pancreas Society, 27 : 113- 
120, 2012.

23. Sankaran SJ, Xiao AY, Wu LM, et al. Frequency of progression from acute to chronic pancreatitis and risk factors : a meta-analysis. Gastroenterology, 149 : 1490-1500, 2015.

24. Lmoto M, Dimagno EP. Cigarette smoking increases the risk of pancreatic calcification in lateonset but not early-onset idiopathic chronic pancreatitis. Pancreas, 21 : 115-119, 2000.

25. Maisonneuve P, Frulloni L, Mullhaupt B, et al. Impact of smoking on patients with idiopathic chronic pancreatitis. Pancreas, 33 : 163-168, 2006.

26. Law R, Parsi M, Lopez R, et al. Cigarette smoking is independently associated with chronic pancreatitis. Pancreatology, 10 : 54-59, 2010.

27. Andriulli A, Botteri E, Almasio PL, et al. Smoking as a cofactor for causation of chronic pancreatitis : a meta-analysis. Pancreas, 39 : 1205-1210, 2010.

28. Klöppel G, Maillet B. The morphological basis for the evolution of acute pancreatitis into chronic pancreatitis. Virchows Archiv A Pathol Anat, 420 : 1-4, 1992.

29. Ueda T, Kuroda Y, Takeyama Y, et al. Long-term outcome of acute pancreatitis. The Journal of Japan Pncreas Society, 20 : 455-464, 2005.

30. Yasuda T, Ueda T, Takeyama Y, et al. Long-term outcome of severe acute pancreatitis. J Hepatobiliary Pancreat Surg, 15 : 397-402, 2008.

31. Ammann RW, Muellhaupt B, Meyenberger C, et al . Alcoholic nonprogressive chronic pancreatitis : prospective long-term study of a large cohort with alcoholic acute pancreatitis (1976-1992). Pancreas, 9 : 365-373, 1994.

32. Lankisch PG, Breuer N, Bruns A, et al. Natural history of acute pancreatitis : a long-term population-based study. Am J Gastroenterol, 104 : 2797-2805, 2009.

33. Yadav D, O'Connell M, Papachristou GI. Natural history following the first attack of acute pancreatitis. Am J Gastroenterol, 107 : 10961103, 2012.

34. Nøjgaard C, Becker U, Matzen P, et al. Progression from acute to chronic pancreatitis : prognostic factors, mortality, and natural course. Pancreas, 40 : 1195-1200, 2011.

35. Kumar S, Ooi CY, Werlin S, et al. Risk factors associated with pediatric acute recurrent and chronic pancreatitis : Lessons From INSPPIRE. JAMA Pediatr, 170 : 562-569, 2016.

36. Ikeda M, Sato T, Morozumi A, et al. Morphologic changes in the pancreas detected by screening ultrasonography in a mass survey, with special refer- ence to main duct dilatation, cyst formation, and calcification. Pancreas, 9 : 508-512, 1994.

37. Rajan E, Clain JE, Levy MJ, et al. Age-related changes in the pancreas identified by EUS : a prospective evaluation. Gastrointest Endosc, 61 : 401-406, 2005.

38. Detlefsen S, Sipos B, Feyerabend B, et al. Pancreatic fibrosis associated with age and ductal papillary hyperplasia. Virchows Arch, 447 : 800805, 2005.

39. Chantarojanasiri T, Hirooka Y, Ratanachu-Ek T, et al. Evolution of pancreas in aging : degenerative variation or early changes of disease? J Med Ultrason, 42 : 177-183, 2015.

40. Janssen J, Papavassiliou I. Effect of aging and diffuse chronic pancreatitis on pancreas elasticity evaluated using semiquantitative EUS elastography. Ultraschall Med, 35 : 253-258, 2014.

41. Wang LW, Li ZS, Li SD, et al. Prevalence and clinical features of chronic pancreatitis in China : a retrospective multicenter analysis over 10 years. Pancreas, 38 : 248-254, 2009.

42. Gu ZY, Zhang KH. Chronic pancreatitis in China : etiology and management. World J Surg, 14: 28-31, 1990.

43. Hardt PD, Bretz L, Krauss A, et al. Pathological pancreatic exocrine function and duct morphology in patients with cholelithiasis. Dig Dis Sci, 46 : 536-539, 2001.

44. Misra SP, Gulati P, Choudhary V, et al. Pancreatic duct abnormalities in gallstone disease : an endoscopic retrograde cholangiopancreaticography study. Gut, 31 : 1073-1075, 1990.

45. Okazaki K, Yamamoto Y, Nishimori I, et al. Motility of the sphincter of Oddi and pancreatic main ductal pressure in patients with alcoholic, gallstoneassociated, and idiopathic chronic pancreatitis. Am J Gastroenterol, 83 : 820-826, 1988.

46. Joergensen A, Thuesen B. Chronic obstructive pancreatitis associated with gallstone in a child. Acta Chir Scand, 149 : 805-806, 1983.

47. Yadav D, Lowenfels AB. The epidemiology of pancreatitis and pancreatic cancer. Gastroenterology, 144 : 1252-1261, 2013.

48. Ammann RW. A clinically based classification system for alcoholic chronic pancreatitis : summary of an international workshop on chronic pancreatitis. Pancreas, 14 : 215-221, 1997.

49. Durbec JP, Sarles H. Multicenter survey of the etiology of pancreatic diseases. Relationship between the relative risk of developing chronic pancreatitis and alcohol, protein and lipid consumption. Digestion, 18 : 337-350, 1978. 